\title{
Analisis Arus Bocor pada Sistem PLTS Terhubung ke Jaringan Tanpa Transformator Terhadap Keselamatan Manusia
}

\author{
Diah Permata ${ }^{1}$, Hekson Yulian $\mathrm{N}^{2}$, Endah Komalasari ${ }^{3}$ \\ ${ }^{123}$ Jurusan Teknik Elektro Universitas Lampung, Bandar Lampung \\ J1. Prof. Sumantri Brojonegoro No.1 Bandar Lampung 35145 \\ ${ }^{1}$ diah.permata@eng.unila.ac.id \\ 2hekson30.nababan@gmail.com \\ 3endah.komalasari@eng.unila.ac.id
}

Intisari - Sistem PLTS yang terhubung ke jaringan tanpa transformator merasakan arus bocor akibat adanya kapasitansi parasitik pada panel surya yang diketanahkan dan hubungan galvanis antara sumber DC dan jaringan. Arus bocor berbahaya bagi keselamatan manusia yang menyentuh panel surya. Penelitian ini menghitung arus bocor melalui simulasi menggunakan Matlab. Rangkaian simulasi terdiri dari sumber DC PLTS, inverter satu fasa, sumber AC jaringan, filter dan kapasitansi parasitik. Kapasitansi Parasitik dimodelkan dengan sebuah kapasitor tunggal. Kondisi panel basah atau kering memberikan nilai kapasitansi yang berbeda. Hasil simulasi menunjukkan bahwa kondisi panel basah menghasilkan arus bocor sepuluh kali lebih tinggi dari kondisi panel kering. Arus bocor pada kedua kondisi masih dibawah batas maksimum standar keselamatan mengacu pada DIN VDE 0126-1-1.

Kata kunci - arus bocor, PLTS, kapasitansi parasit, arus common mode, inverter.

Abstract - PV system on grid transformerless experiences leakage current due to parasitic capacitance on grounded-PV panel and a galvanic connection between the grid and the dc source. Leakage current is harmful for human who touch the PV panel. This research calculates the leakage current via simulation using Matlab. Simulation circuit consists of DC source as PV system, one phase inverter, grid AC source, filter and parasitic capacitance. A single capacitor is used to model parasitic capacitance. Wet and dry condition of PV panel generate a different capacitance. The simulation results show wet PV panel produce a leakage current ten times higher than that in dry PV panel. The leakage curent either in wet and dry condition are below maximum limit of DIN VDE 0126-1-1 safety standard.

Keywords - leakage current, PV system, parasitic capacitance, common mode current, inverter.

\section{PENDAHULUAN}

Sistem PLTS yang terhubung ke jaringan PLN tanpa transformator (on grid transformerless) berkembang pesat di luar negeri karena harganya yang relatif murah dan ukurannya yang ringkas. Di Indonesia, sistem PLTS on grid transformerless juga mulai banyak dipasang terlebih dengan adanya Peraturan Menteri ESDM No. 49 tahun 2018 yang mengizinkan konsumen PLN memasang PLTS atap dan mengekspor daya listriknya ke PLN.

Di Indonesia, kementrian ESDM merekomendasikan bahwa bingkai panel surya harus diketanahkan untuk mencegah adanya beda potensial antara bingkai dan sistem pentanahan terutama untuk sistem yang menggunakan inverter tanpa transformator. Hal ini bertujuan untuk melindungi manusia terhadap tegangan sentuh [1]. Jika bingkai panel surya diketanahkan maka akan timbul kapasitansi parasitik antara panel surya dengan tanah. Akibat adanya kapasitansi parasitik antara panel surya dan tanah, perbedaan potensial yang disebabkan oleh aksi switching dari inverter menyuntikkan arus ke tanah (ground capacitive current) [2]. Selain itu, sistem PLTS terhubung ke jaringan tanpa transformator menimbulkan hubungan 
galvanis antara sumber DC dan jaringan sehingga arus bocor akan timbul [3].

Pada PLTS yang terhubung ke jaringan tanpa menggunakan transformator seperti ditampilkan pada gambar 1, rangkaian resonansi akan terbentuk jika panel surya ditanahkan. Rangkaian resonansi terdiri dari kapasitansi parasitik, inverter, filter dan impedansi jaringan. Pada panel surya nilai kapasitansi parasitik cukup besar sehingga arus bocor ke tanah dapat mencapai nilai yang cukup tinggi. Arus bocor yang mengalir pada rangkaian menyebabkan kerugian seperti menambah rugi-rugi sistem, menimbulkan interferensi elektromagnetik (harmonisa), dan membahayakan keselamatan [3].

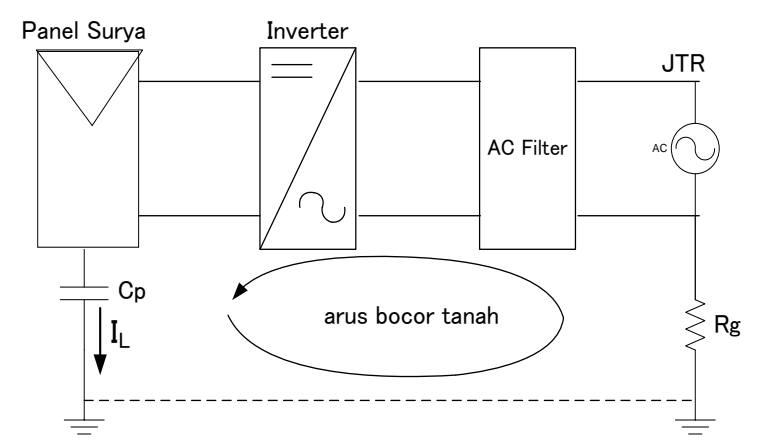

Gbr. 1. Diagram segaris dari sistem PLTS terhubung jaringan tanpa transformator

Penelitian ini menghitung arus bocor pada sistem PLTS atap dengan kapasitas $2200 \mathrm{Wp}$. Kapasitas PLTS dipilih berdasarkan pertimbangan bahwa rata-rata pelanggan listrik PLN untuk rumah tangga saat ini menggunakan kapasitas kWh meter $2200 \mathrm{VA}$. Besar arus bocor dipengaruhi oleh kondisi panel surya apakah dalam keadaan basah atau kering. Oleh karena itu pada penelitian ini kondisi panel juga diperhitungkan. Arus bocor kemudian dibandingkan dengan standar keselamatan yang mengacu pada DIN VDE 0126-1-1.

\section{MODEL SIMULASI}

Perhitungan arus bocor pada sistem PLTS dilakukan melalui simulasi menggunakan Matlab. Semua komponen dalam sistem PLTS yaitu: sumber DC, inverter satu fasa, filter, kapasitansi parasitik dan sumber AC dari jaringan dimodelkan dalam rangkaian pengganti. Adapun model dari masingmasing komponen adalah sebagai berikut:

A. Panel Surya

Panel surya dimodelkan dengan sumber DC pada Simscape Electrical. Besar tegangan adalah $312 \mathrm{~V}_{\mathrm{DC}}$ sehingga output PLTS setelah dikonversikan oleh inverter sama dengan tegangan jaringan PLN yaitu 220 V AC. Gambar 2 merupakan model sumber DC.

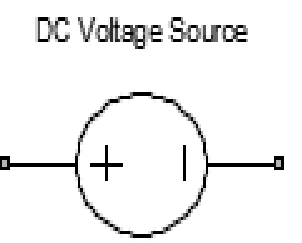

Gbr. 2 Model sumber DC

\section{B. Inverter}

Penelitian ini menggunakan inverter satu fasa dengan topologi full bridge dengan modulasi bipolar sinusoidal pulse width modulation (SPWM). Inverter jenis ini banyak diteliti dan direkomendasikan antara lain oleh [4] untuk mengurangi masalah arus bocor. Gelombang sinusoidal digunakan sebagai sinyal referensi dan gelombang kotak sebagai sinyal pembawa. Tiap mosfet bekerja pada frekuensi switching $18 \mathrm{kHz}$.

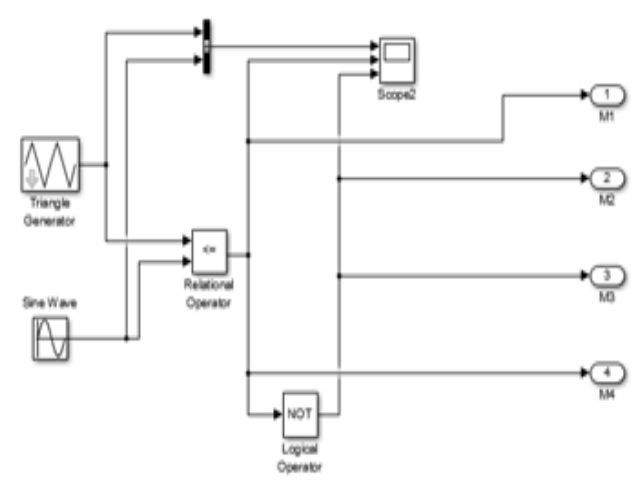

Gbr. 3 Rangkaian inverter dengan modulasi bipolar SPWM

\section{Jaringan Tegangan Rendah}

Jaringan tegangan rendah (JTR) dimodelkan dengan sebuah model sumber AC dengan tegangan $220 \mathrm{~V}$ dan frekuensi 50 Hz. Penelitian ini memperhitungkan tanahan pentanahan $\left(R_{g}\right)$ [5]-[6]. Nilai tahanan pentanahan diasumsikan sebesar $5 \Omega$ sesuai standar PUIL 2000:68. Model JTR dengan 
tahanan pentanahan ditunjukkan pada gambar 4.

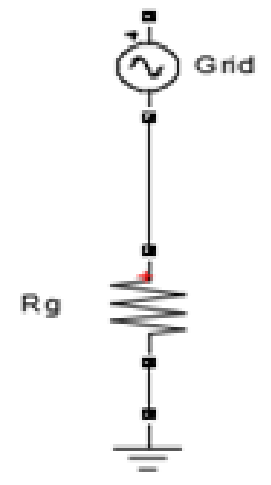

Gbr. 4 Model JTR dengan tanahan pentanahan

\section{Kapasitansi Parasitik}

Kapasitansi parasitik menggunakan model kapasitor tunggal yang banyak digunakan oleh peneliti dalam kajian arus bocor tetapi tiap peneliti mengusulkan nilai kapasitansi yang berbeda-beda. Nilai kapasitansi bervariasi antara $7 \mathrm{nF} / \mathrm{kW}$ sampai 220 $\mathrm{nF} / \mathrm{kW}$ [3]-[7]. Penelitian ini menggunakan nilai kapasitansi sebesar $100 \mathrm{nF} / \mathrm{kW}$ untuk kondisi panel kering yang diusulkan oleh [4][5],[8]-[9]. Jika kondisi panel basah, kapasitansi parasitik menjadi lebih besar yaitu $1 \mu \mathrm{F} / \mathrm{kW}$ [10]. Sehingga nilai kapasitansi parasitik untuk PLTS kapasitas $2200 \mathrm{Wp}$ adalah $220 \mathrm{nF}$ untuk kondisi panel kering dan 2,2 $\mu \mathrm{F}$ untuk kondisi panel basah. Gambar 5 menunjukkan kapasitor tunggal yang merupakan model kapasitansi parasitik.

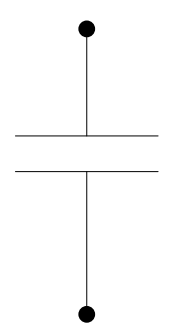

Gbr. 5 Model kapasitansi parasitik

\section{E. Filter}

Penelitian ini menggunakan LCL Filter yang direkomendasikan oleh [3]. Diagram segaris sistem PLTS terhubung jaringan tanpa transformator yang ditampilkan pada gambar 1 dimodelkan dalam rangkaian simulasi pada gambar 6. Adapun nilai parameter dari masing-masing komponen ditampilkan pada tabel 1 .

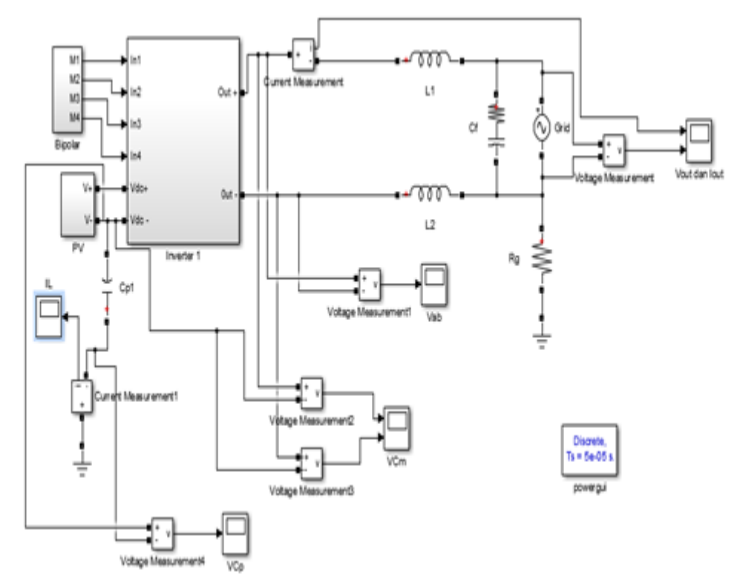

Gbr. 6 Rangkaian simulasi sistem PLTS

Tabel 1. Nilai parameter dari komponen PLTS

\begin{tabular}{|c|c|}
\hline Parameter & Nilai \\
\hline $\mathrm{V}_{\mathrm{DC}}$ & $312 \mathrm{~V}$ \\
\hline $\mathrm{P}$ & $2.2 \mathrm{~kW}$ \\
\hline $\mathrm{f}_{\text {grid }}$ & $50 \mathrm{~Hz}$ \\
\hline $\mathrm{f}_{\text {inv }}$ & $18 \mathrm{kHz}$ \\
\hline $\mathrm{V}_{\text {grid }}$ & $220 \mathrm{~V}$ \\
\hline $\mathrm{C}_{\text {p-kering }}$ & $220 \mathrm{nF}$ \\
\hline $\mathrm{C}_{\text {p-basah }}$ & $2,2 \mu \mathrm{F}$ \\
\hline $\mathrm{C}_{\text {filter }}$ & $4.7 \mu \mathrm{F}$ \\
\hline $\mathrm{L}_{\text {filter }}$ & $3 \mathrm{mH}$ \\
\hline $\mathrm{R}_{\mathrm{g}}$ & $5 \Omega$ \\
\hline
\end{tabular}

\section{HASIL DAN PEMBAHASAN}

Rangkaian simulasi dijalankan menggunakan perangkat lunak Matlab. Kondisi panel basah dan kering disimulasikan dengan mengganti nilai kapasitansi parasitik pada kapasitor tunggal $C_{\mathrm{p}}$ menjadi $220 \mathrm{nF}$ untuk kondisi panel kering dan 2,2 $\mu \mathrm{F}$ untuk kondisi panel basah. Besaran tegangan yang diukur adalah tegangan output inverter $V_{\mathrm{ab}}$, tegangan common mode inverter $V_{\mathrm{cm}}$, dan tegangan jaringan $V_{\text {out. }}$ Sedangkan besaran arus yang diukur adalah arus yang mengalir pada kapasitor tunggal $I_{\mathrm{L}}$, dan arus output inverter $I_{\text {out. }}$ Bentuk gelombang untuk masing-masing tegangan dan arus ditunjukkan pada gambar $7-11$. 


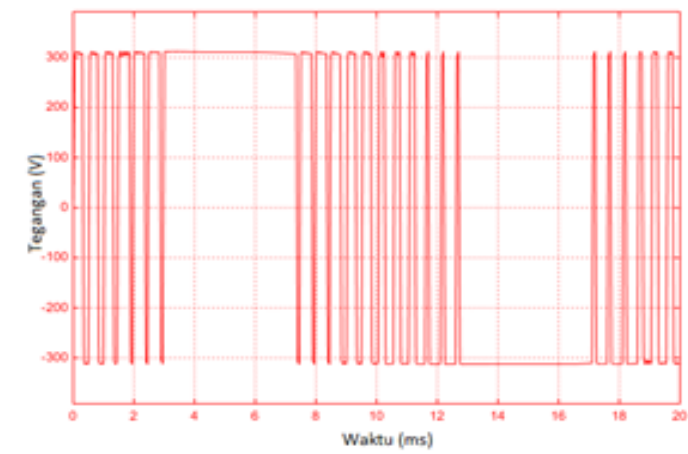

Gbr. 7 Tegangan output inverter $\left(V_{\mathrm{ab}}\right)$

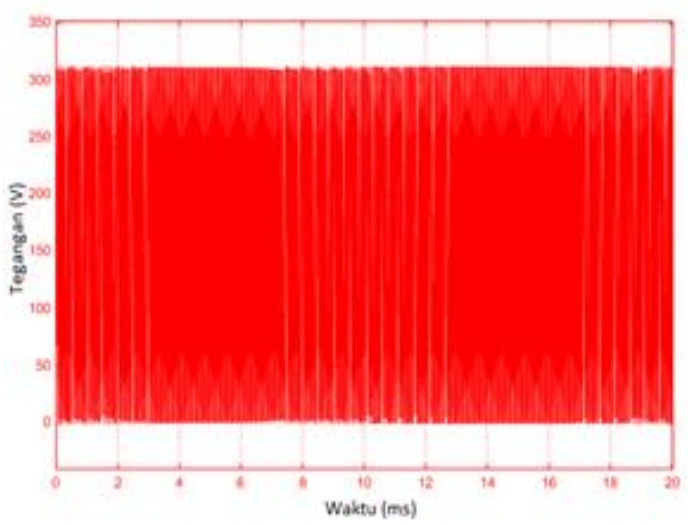

Gbr. 8 Tegangan common mode $\left(V_{\mathrm{cm}}\right)$
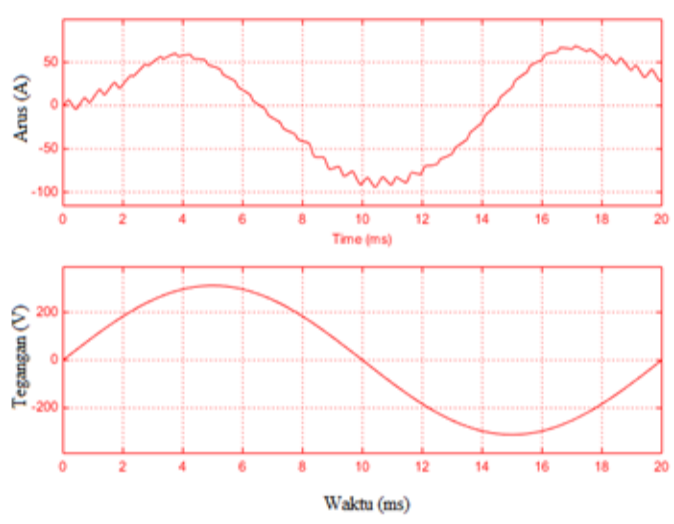

Gbr. 9 Tegangan $V_{\text {out }}$ dan arus $I_{\text {out }}$ pada jaringan

Tegangan $V_{\mathrm{ab}}, V_{\mathrm{cm}}$, dan $V_{\text {out }}$ serta arus $I_{\text {out }}$ tidak dipengaruhi oleh besar kapasitansi parasitik dari panel sehingga hasil simulasi menunjukkan bentuk gelombang dan nilai yang hampir sama untuk kondisi panel basah maupun kering. Besar tegangan puncak $V_{\mathrm{ab}}$ dan $V_{\mathrm{cm}}$ yang ditunjukkan pada gambar 7 dan 8 adalah $312,71 \mathrm{~V}$ dan $312,74 \mathrm{~V}$. Nilai tegangan efektif (rms) untuk $V_{\mathrm{ab}}$ dan $V_{\mathrm{cm}}$ adalah 219,51 V dan 220,13 V. Gelombang arus dan tegangan pada jaringan ( $I_{\text {out }}$ dan $\left.V_{\text {out }}\right)$ yang ditampilkan pada gambar 9 mempunyai nilai efektif (rms) sebesar 51,94 A dan $220 \mathrm{~V}$.
Arus $\mathrm{I}_{\text {out }}$ adalah arus yang disuplai oleh inverter sehingga bentuk gelombang masih memiliki sedikit riak akibat pengaruh frekuensi tinggi dari modulasi inverter.

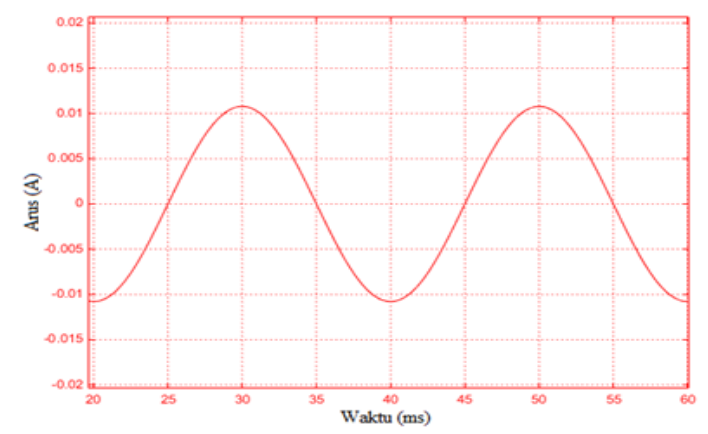

Gbr. 10 Arus bocor $I_{\mathrm{L}}$ yang mengalir pada kapasitor tunggal kondisi panel kering

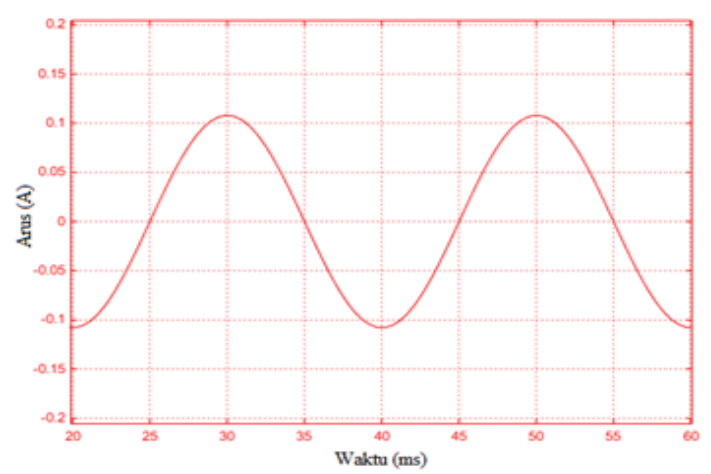

Gbr. 11 Arus bocor $I_{\mathrm{L}}$ yang mengalir pada kapasitor tunggal kondisi panel basah

Gelombang arus bocor $I_{\mathrm{L}}$ pada kondisi panel kering dan basah yang ditampilkan pada gambar 10 dan 11 dicuplik pada kondisi steady state mulai $\mathrm{t} \geq 20 \mathrm{~ms}$. Nilai puncak arus bocor $I_{\mathrm{L}}$ untuk kondisi kering dan basah secara berturut-turut adalah $10,78 \mathrm{~mA}$ dan 108,02 mA Sedangkan nilai efektif (rms) arus bocor $I_{\mathrm{L}}$ untuk kondisi panel kering sebesar 7,52 mA dan 75,8 mA untuk kondisi panel basah. Hasil perhitungan dari simulasi menunjukkan bahwa besar arus bocor pada kondisi panel basah 10 kali lebih tinggi dibandingkan dengan kondisi panel kering. Hal ini sesuai dengan nilai kapasitansi parasitik dari kapasitor tunggal $C_{\mathrm{p}}$ pada kondisi basah 10 kali lebih tinggi dari nilai pada kondisi kering.

Tujuan dari penelitian adalah untuk menganalisis apakah nilai arus bocor yang mengalir pada PLTS atap kapasitas $2200 \mathrm{Wp}$ memenuhi standar keselamatan yang mengacu pada DIN VDE 0126-1-1. 
Standar mensyaratkan besar arus bocor yang mengalir tidak boleh melebihi $300 \mathrm{~mA}$ (nilai puncak) [11]. Nilai puncak arus bocor $I_{\mathrm{L}}$ yang didapat dari penelitian ini adalah 10,78 mA untuk kondisi panel kering dan 108,02 mA untuk kondisi panel basah. Sehingga berdasarkan standar DIN VDE 0126-1-1 yang dikutip dari [11] arus bocor $I_{\mathrm{L}}$ yang mengalir pada PLTS masih memenuhi standar keselamatan untuk kondisi panel basah ataupun kering. Arus bocor yang mengalir walaupun pada kondisi panel basah tidak berbahaya bagi keselamatan manusia.

\section{KESIMPULAN}

Penelitian ini sudah menghitung besar arus bocor pada PLTS dengan kapasitas $2200 \mathrm{Wp}$ yang terhubung ke jaringan tegangan rendah PLN tanpa menggunakan transformator. Arus bocor yang mengalir pada PLTS pada kondisi panel basah sepuluh kali lebih tinggi dari kondisi panel kering. Walaupun begitu nilai arus bocor pada kondisi panel basah dan kering masih memenuhi standar keselamatan.

\section{REFERENSI}

[1] B. Ramadhani, Instalasi Pembangkit Listrik Tenaga Surya Dos \& Don'ts. Jakarta: Deutsche Gesellschaft für Internationale Zusammenarbeit (GIZ) GmbH Energising, 2018.

[2] M. Calais, V. G. Agelidis, and M. Meinhardt, "Multilevel converters for single-phase grid connected photovoltaic systems: An overview," Sol. Energy, vol. 66, no. 5, pp. 325335, 1999.

[3] Ó. López et al., "Eliminating ground current in a transformerless photovoltaic application," IEEE Trans. Energy Convers., vol. 25, no. 1, pp. 140-147, 2010.

[4] Z. Ahmad and S. N. Singh, "Single phase transformerless inverter topology with reduced leakage current for grid connected photovoltaic system," Electr. Power Syst. Res., vol. 154, pp. 193-203, 2018.

[5] H. Xiao and S. Xie, "Leakage current analytical model and application in single-phase transformerless photovoltaic grid-connected inverter," IEEE Trans. Electromagn. Compat., vol. 52, no. 4, pp. 902-913, 2010.

[6] L. Ma, F. Tang, F. Zhou, X. Jin, and Y. Tong, "Leakage current analysis of a single-phase transformer-less PV inverter connected to the grid," 2008 IEEE Int. Conf. Sustain. Energy Technol. ICSET 2008, no. September 2014, pp. 285-289, 2008.

[7] D. Barater, G. Buticchi, E. Lorenzani, and C. Concari, "Active commonmode filter for ground leakage current reduction in grid-connected PV converters operating with arbitrary power factor," IEEE Trans. Ind. Electron., vol. 61, no. 8, pp. 3940 3950, 2014.

[8] T. Kerekes, R. Teodorescu, P. Rodríguez, G. Vázquez, and E. Aldabas, "A New high-efficiency single-phase transformerless PV inverter topology," IEEE Trans. Ind. Electron., vol. 58, no. 1, pp. 184-191, 2011.

[9] Y. Zhou and H. Li, "Analysis and suppression of leakage current in cascaded-multilevel- inverter-based PV systems," IEEE Trans. Power Electron., vol. 29, no. 10, pp. 52655277, 2014.

[10] R. Araneo, S. Lammens, M. Grossi, and S. Bertone, "EMC issues in highpower grid-connected photovoltaic plants," IEEE Trans. Electromagn. Compat., vol. 51, no. 3 PART 2, pp. 639-648, 2009.

[11] G. Vazquez, T. Kerekes, J. Rocabert, P. Rodríguez, R. Teodorescu, and D. Aguilar, "A photovoltaic three-phase topology to reduce common mode voltage," IEEE Int. Symp. Ind. Electron., pp. 2885-2890, 2010. 